\title{
Assessment on the Diagnostic Capacity for Parasitic Diseases of Health Facilities - China, 2019
}

\author{
Qiang Wang'; Jing Xu'; Yuwan Hao'; Tian Tian'; Zelin Zhu'; Xueqiang Zhang'; Liying Wang'; \\ Shaohong Chen'; Jiaxu Chen'; Ning Xiao'; Shizhu Li ${ }^{1}{ }^{1, *}$
}

\section{Summary \\ What is already known about this topic? \\ Morbidity and prevalence of several major parasitic diseases have been declining in China. To reduce the disease burden of parasitic diseases and protect public health security, conducting accurate diagnoses following timely treatment is important. \\ What is added by this report? \\ In the national competition held in 2019 , the overall accuracy rates of participants for theoretical knowledge and slides interpretation for parasitic diseases were $80.44 \%$ and $66.87 \%$, respectively. Significant differences in the accuracy rates of detecting schistosomiasis or malaria existed between endemic areas and non-endemic areas, respectively. \\ What are the implications for public health practice? \\ The study results will help policymakers and health managers to identify the gaps in parasitic diseases, help to strengthen diagnostic capacity, and improve quality of control programs.}

China used to be overloaded by the heavy burden caused by parasitic diseases. However, through several decades of effort, the number of cases and the prevalence of parasitic diseases had declined dramatically nationwide (1-3). However, misdiagnosis of parasitic diseases was reported from occasionally, especially for imported cases or asymptomatic cases with light infections. To understand the gap in diagnostic capacity that exists for parasitic diseases, a nationwide competition was conducted in August 2019 by the National Health Commission (NHC) through a paper test and interpretation of slides containing parasite worms or eggs. Generally, technicians grasped the knowledge of parasitic disease well but their practical skills for slides interpretation were not satisfactory with an overall accuracy rate of $66.87 \%$. As parasitological methods relying on interpreting slides were still the gold standard for diagnosing parasitic diseases, further capacity building for diagnosis, especially parasitological methods, should be strengthened to avoid misdiagnosis of patients and provide accurate data for policymaking.

In August 2019, a national competition for parasitic diseases was held by the NHC in Changchun City of Jilin Province. A total of 32 teams with 128 technicians attended the competition. Each team was composed of four professional staff members, with at least one being from hospitals and two from agencies below the provincial level. All participants were aged less than or equal to 45 years old. The competition consisted of 2 parts: 1) theoretical knowledge on the life cycle of common parasites, their etiology and diagnosis, and control and prevention strategies of several parasitic diseases were evaluated through a paper test composed of 50 questions featured as singlechoice, multiple-choice, and true or false categories; and 2) the technical skills for interpretation of blood smear slides and Kato-Katz thick smear slides were examined. All slides and the reference answers were prepared by the National Institute of Parasitic Disease (NIPD) of China CDC.

All assessment activities were conducted in parallel in single blind manner. The original results of each participant were entered into a computer by Microsoft Excel (version 2013, Microsoft Corp, Redmond, USA) and descriptive statistics was conducted by SPSS software (version 20, IBM Corp, Armonk, USA) to describe the general information of participants. The accuracy rate was calculated as the number of questions answered accurately divided by the total number of questions, or the accumulated number of parasite species in slides interpreted accurately divided by the total number of referenced parasite species provided by NIPD. Chi-squared statistics were used to compare the values between or among subgroups. The level of statistical significance was defined as $P<0.05$.

In total, 128 participants from 30 provincial-level administrative divisions (PLADs), Xinjiang Production and Construction Corps, and Chinese General Administration of Customs attended the competition. 
Overall, $28.9 \%(37 / 128)$ of participants were male and $71.1 \%$ (91/128) were female. All participants were aged with a mean value of $32.43 \pm 4.95$ years old. The majority of participants $(96.1 \%, 123 / 128)$ were junior staff with primary or middle level professional titles, while the rest were senior staff. Among of them, 82 participants were working at agencies of public health while 46 participants were from hospitals.

In the theoretical knowledge assessment, the accuracy rate was $80.44 \%(5,148 / 6,400)$ for all participants but varied from $38.00 \%(19 / 50)$ to $98.00 \%$ (49/50). Chi-square analysis showed that the females had higher accuracy rates than the males $\left(\chi^{2}=14.139, P<0.01\right)$ while the accuracy rate in participants from public health agencies was higher than that from hospitals $\left(\chi^{2}=8.374, \quad P<0.01\right)$. Significant differences were also detected when analyzing accuracy rates by strata of professional titles and agencies $\left(\chi^{2}=8.571, \chi^{2}=24.023, P<0.05\right)$. But no difference in accuracy rate was found among different age groups $\left(\chi^{2}=2.442, P>0.05\right)$ (Table 1).

For the knowledge points, the accuracy rates regarding to diagnosis, detection technology, the life cycle of parasites, and control and prevention of parasitic diseases were $84.90 \%(1,304 / 1,536), 84.01 \%$ $(1,398 / 1,664), 83.52 \%(1,176 / 1,408)$, and $70.87 \%$ $(1,270 / 1,792)$, respectively, presenting significant differences $\left(\chi^{2}=145.682, P<0.05\right)$. In addition, the accuracy rates of answers to questions related to the diagnosis of schistosomiasis, malaria, echinococcosis, other parasitic disease, and comprehensive issues were
$84.38 \% \quad(1,080 / 1,280), \quad 83.98 \% \quad(1,075 / 1,280)$, $76.72 \%(982 / 1,280), 81.75 \%(1,465 / 1,792)$, and $71.09 \%(546 / 768)$, respectively, showing significant difference $\left(\chi^{2}=78.673, P<0.05\right)$.

For the interpretation of slides, the accuracy rate for thick smear slides and blood smear slides was $67.19 \%$ $(2,097 / 3,121)$ and $65.31 \%$ (418/640), respectively, with the overall accuracy rate being $66.87 \%$ $(2,515 / 3,761)$ (Table 2). Individually, the accuracy rate for the interpretation of thick smear slides ranged from $10 \%(3 / 30)$ to $96.55 \%$ (28/29); 22 participants had a $100 \%$ accuracy rate, but 4 participants provided all wrong answers for blood smear slides interpretation. The average accuracy rates did not differ significantly among agencies $\left(\chi^{2}=5.494, \chi^{2}=0.073, P>0.05\right)$, but females, younger professional staff, and senior staff had higher accuracy rates $(P<0.05)$.

In analyzing the accuracy rates by helminth species, the highest accuracy was $87.50 \%$ (420/480) for the detection of Clonorchis sinensi, followed by $83.73 \%$ (669/799) for Ascarias spp. The lowest accuracy rate was $25.89 \%$ (124/479) for detection of Schistosoma japonicum (Table 3). Significant differences in accuracy rates were detected among helminth species identification $\quad\left(\chi^{2}=593.544, \quad P<0.05\right) . \quad$ For identification of plasmodium species, the accuracy rate for detecting Plasmodium malariae, P. falciparum, $P$. vivax, and negative slides were $57.50 \%(23 / 40)$, $60.47 \%$ (179/296), $69.64 \%(117 / 168)$, and $72.79 \%$ (99/136), respectively, presenting significant differences $\left(\chi^{2}=8.888, P<0.05\right)$. The accuracy rate of

TABLE 1. The accuracy rates of 128 participants for knowledge test related to parasitic diseases in China, 2019.

\begin{tabular}{|c|c|c|c|c|c|c|}
\hline Categories & Features & $\begin{array}{c}\text { No. } \\
\text { participants }\end{array}$ & $\begin{array}{l}\text { No. questions } \\
\text { answered }\end{array}$ & $\begin{array}{c}\text { No. questions answered } \\
\text { accurately }\end{array}$ & Accuracy rate $(\%)$ & Chi-square test \\
\hline Total & & 128 & 6,400 & 5,148 & 80.44 & \\
\hline \multirow{2}{*}{ Gender } & Male & 37 & 1,850 & 1,434 & 77.51 & \multirow{2}{*}{$x^{2}=14.139, P<0.001$} \\
\hline & Female & 91 & 4,550 & 3,714 & 81.63 & \\
\hline \multirow{3}{*}{ Age, years } & $\leq 30$ & 43 & 2,150 & 1,706 & 79.35 & \multirow{3}{*}{$X^{2}=2.442, P=0.295$} \\
\hline & $31-40$ & 72 & 3,600 & 2,915 & 80.97 & \\
\hline & $\geq 41$ & 13 & 650 & 527 & 81.08 & \\
\hline \multirow{3}{*}{$\begin{array}{l}\text { Professional } \\
\text { title }\end{array}$} & Primary & 74 & 3,700 & 2,933 & 79.27 & \multirow{3}{*}{$X^{2}=8.571, P=0.014$} \\
\hline & Middle & 49 & 2,450 & 2,004 & 81.80 & \\
\hline & High & 5 & 250 & 211 & 84.40 & \\
\hline \multirow{3}{*}{ Agency level } & Province & 19 & 950 & 709 & 74.63 & \multirow{3}{*}{$x^{2}=24.023, P<0.001$} \\
\hline & City & 40 & 2,000 & 1,624 & 81.20 & \\
\hline & County & 69 & 3,450 & 2,815 & 81.59 & \\
\hline \multirow{2}{*}{$\begin{array}{l}\text { Agency } \\
\text { feature }\end{array}$} & Public health & 82 & 4,100 & 3,342 & 81.51 & \multirow{2}{*}{$X^{2}=8.374, P=0.004$} \\
\hline & Hospital & 46 & 2,300 & 1,806 & 78.52 & \\
\hline
\end{tabular}


TABLE 2. The accuracy rates of participants for slides interpretation in China, 2019.

\begin{tabular}{|c|c|c|c|c|c|c|}
\hline Categories & Features & $\begin{array}{c}\text { No. } \\
\text { participants }\end{array}$ & $\begin{array}{l}\text { Accumulated } \\
\text { slides number }\end{array}$ & $\begin{array}{l}\text { Accumulated slides number } \\
\text { judged parasites correctly }\end{array}$ & Accuracy rate $(\%)$ & Chi-square test \\
\hline Total & & 128 & 3,761 & 2,515 & 66.87 & \\
\hline \multirow{2}{*}{ Gender } & Male & 37 & 1,082 & 688 & 63.59 & \multirow{2}{*}{$x^{2}=7.397, P=0.007$} \\
\hline & Female & 91 & 2,679 & 1,827 & 68.20 & \\
\hline \multirow{3}{*}{ Age, years } & $\leq 30$ & 43 & 1,268 & 896 & 70.66 & \multirow{3}{*}{$X^{2}=12.655, P=0.002$} \\
\hline & $31-40$ & 72 & 2,114 & 1,377 & 65.14 & \\
\hline & $\geq 41$ & 13 & 379 & 242 & 63.85 & \\
\hline \multirow{3}{*}{$\begin{array}{l}\text { Professional } \\
\text { title }\end{array}$} & Primary & 74 & 2,173 & 1,477 & 67.97 & \multirow{3}{*}{$X^{2}=7.614, P=0.020$} \\
\hline & Middle & 49 & 1,441 & 930 & 64.54 & \\
\hline & High & 5 & 147 & 108 & 73.47 & \\
\hline \multirow{3}{*}{ Agency level } & Province & 19 & 559 & 351 & 62.79 & \multirow{3}{*}{$x^{2}=5.494, P=0.064$} \\
\hline & City & 40 & 1,171 & 801 & 68.40 & \\
\hline & County & 69 & 2,031 & 1,363 & 67.11 & \\
\hline \multirow{2}{*}{$\begin{array}{l}\text { Agency } \\
\text { feature }\end{array}$} & $\mathrm{CDC}$ & 82 & 2,423 & 1,624 & 67.02 & \multirow{2}{*}{$x^{2}=0.073, P=0.787$} \\
\hline & Hospital & 46 & 1,338 & 891 & 66.59 & \\
\hline
\end{tabular}

Note: CDC: Center for Disease Control and Prevention.

TABLE 3. The accuracy rates of 128 participants for parasites identification based on slides interpretation in China, 2019.

\begin{tabular}{|c|c|c|c|c|}
\hline Types of slides & Types of parasites in slides & $\begin{array}{l}\text { Accumulated number } \\
\text { of slides }\end{array}$ & $\begin{array}{l}\text { Accumulated number of } \\
\text { slides judged correctly }\end{array}$ & $\begin{array}{c}\text { Accuracy rate } \\
(\%)\end{array}$ \\
\hline Total & & 3,761 & 2,515 & 66.87 \\
\hline \multirow{10}{*}{ Thick smear slides } & Schistosoma japonicum & 479 & 124 & 25.89 \\
\hline & Trichuris trichiura & 161 & 97 & 60.25 \\
\hline & Paragonimus & 320 & 206 & 64.38 \\
\hline & Fasciolopsis & 80 & 64 & 80.00 \\
\hline & Ascarias spp. & 799 & 669 & 83.73 \\
\hline & Enterobius vermicularis & 241 & 183 & 75.93 \\
\hline & Clonorchis sinensis & 480 & 420 & 87.50 \\
\hline & Taeniidae & 240 & 142 & 59.17 \\
\hline & Spirometra mansonia & 321 & 192 & 59.81 \\
\hline & Subtotal & 3,121 & 2,097 & 67.19 \\
\hline \multirow{5}{*}{ Blood smear slides } & Plasmodium falciparum & 296 & 179 & 60.47 \\
\hline & Plasmodium vivax & 168 & 117 & 69.64 \\
\hline & Plasmodium malariae & 40 & 23 & 57.50 \\
\hline & Negatives & 136 & 99 & 72.79 \\
\hline & Subtotal & 640 & 418 & 65.31 \\
\hline
\end{tabular}

participants from schistosomiasis endemic areas for schistosomiasis slides interpretation was $35.87 \%$ (66/184), significantly higher than that of $19.66 \%$ $(58 / 295)$ in participants from non-endemic areas $\left(\chi^{2}=15.517, P<0.01\right)$. Similarly, the accuracy rate of participants from malaria endemic areas for malaria slides interpretation was higher than that of participants from non-endemic areas $[70.00 \%$ (322/460) vs, 53.33\% (96/180), $\left.\chi^{2}=15.863, P<0.01\right]$.

\section{DISCUSSION}

The results from the assessment through nationwide competition on the diagnosis of parasitic diseases showed that technicians grasped the knowledge of parasitic disease generally well, but the interpretation of slides of parasitological methods were not satisfactory. Females demonstrated higher diagnostic capacity than males, but differences of accuracy rates in 
participants also existed among subgroups when analyzing the data by professional title, specific knowledge points, or species of parasites. Significant difference in accuracy rates of detecting schistosomiasis and malaria was also detected between endemic areas and non-endemic areas, respectively.

With the decline of prevalence and infection intensity of local parasitic diseases and increase in the number of imported or emerging parasitic diseases (4-6), misdiagnosis occurred occasionally due to declining conscientiousness or weak skills related to parasitic diseases. The evaluation conducted nationwide by the NHC during 2012-2016 indicated gaps in the diagnosis of parasitic diseases nationwide to control or eliminate parasitic diseases ( 7 ). In past decade, capacity building was strengthened through construction of reference laboratories for parasitic diseases, conducting of training courses, or organizing inter-laboratories comparison (8-9). In this study, we found the diagnostic capacity for parasitic diseases improved but gaps still existed.

From the knowledge test results, the average accuracy rate was higher than $80 \%$, demonstrating a general understanding of knowledge toward parasitic diseases. However, the accuracy rates differed significantly among individuals in the range of $38 \%-98 \%$. Males, staff with first-level professional titles, and staff from hospitals presented lower accuracy rates for knowledge tests. In addition, the accuracy rates of questions among knowledge points and categories of diseases were relatively low in questions related to echinococcosis, comprehensive questions, and the control and prevention of parasitic diseases. The average accuracy rate for the interpretation of slides was $66.87 \%(2,515 / 3,761)$, suggesting big challenges existed in the diagnosis of parasitic diseases. For determination of parasitic species, the accuracy rates were highest for Clonorchis sinensis with an accuracy rate of $87.50 \%$, which may be explained by increased attention on liver diseases in recent decades and the typical features of eggs that can be easily identified (10). The accuracy rates for 2 major parasitic diseases in China including malaria and schistosomiasis were $65.31 \%$ and $25.89 \%$, respectively. Significant differences in accuracy rates existed between endemic and non-endemic area of schistosomiasis and malaria. As malaria has been eliminated in 2021 and schistosomiasis is close to elimination in China, the gap existing in diagnosis should be filled to build capacity building for the prompt finding of endemic cases and imported cases from foreign countries.
There are several limitations in this study. One limitation is that the participants involved in this study only accounted for a small part of medical workers in China. To understand the overall capacity level for diagnosis of parasitic diseases, further assessment should be conducted extensively. The other one is that the questionnaire test and slides used hadn't received scientific assessment. In addition, the results for both parts were analyzed separately and couldn't assess the overall capacity of participants comprehensively. It should be noted that all participants in this competition were recommended or selected by each PLAD and possibly received long periods of training. The actual diagnostic capacity in health facilities across China may be much lower than that reflected in our study and likely could not meet the needs of national control and prevention strategies for parasitic diseases. Further capacity building should be enhanced at all levels through more training courses, especially for parasitological tests as they remain the diagnostic gold standard of parasitic diseases. To ensure the efficiency of diagnosis, external quality assessment and rechecking samples should be considered and conducted during the implementation in the national control programs.

Conflicts of interest: No conflicts of interest.

Acknowledgements: Staff of National Institute of Parasitic Diseases, China CDC, who prepared the reference slides and attended the supervision of the contest.

Funding: National Science Foundation of China (Grant No. 82073619).

doi: $10.46234 / \mathrm{ccdcw} 2021.181$

\#Corresponding author: Shizhu Li, lisz@chinacdc.cn.

${ }^{1}$ National Institute of Parasitic Diseases, Chinese Center for Disease
Control and Prevention (Chinese Center for Tropical Diseases
Research); NHC Key Laboratory of Parasite and Vector Biology;
WHO Collaborating Centre for Tropical Diseases; National Center for
International Research on Tropical Diseases, Shanghai, China.

Submitted: May 28, 2021; Accepted: August 24, 2021

\section{REFERENCES}

1. Xu J, Li SZ, Zhang LJ, Bergquist R, Dang H, Wang Q, et al. Surveillance-based evidence: elimination of schistosomiasis as a public health problem in the Peoples' Republic of China. Infect Dis Poverty 2020;9(1):63. http://dx.doi.org/10.1186/s40249-020-00676-5.

2. Lai SJ, Sun JL, Ruktanonchai NW, Zhou S, Yu JX, Routledge I, et al. Changing epidemiology and challenges of malaria in China towards elimination. Malar J 2019;18(1):107. http://dx.doi.org/10.1186/s12 936-019-2736-8.

3. Li B, Quzhen G, Xue CZ, Han S, Chen WQ, Yan XL, et al. Epidemiological survey of echinococcosis in Tibet Autonomous Region 
of China. Infect Dis Poverty 2019;8(1):29. http://dx.doi.org/10.1186/ s40249-019-0537-5.

4. Fang Y, Zhang Y. Lessons from lymphatic filariasis elimination and the challenges of post-elimination surveillance in China. Infect Dis Poverty 2019;8(1):66. http://dx.doi.org/10.1186/s40249-019-0578-9.

5. Dai SM, Guan Z, Zhang LJ, Lv S, Cao CL, Li SZ, et al. Imported schistosomiasis, China, 2010-2018. Emerg Infect Dis 2020;26(1):17980. http://dx.doi.org/10.3201/eid2601.191250.

6. Zhou XN, Qian MB, Priotto G, Franco JR, Guo JG. Tackling imported tropical diseases in China. Emerg Microbes Infect 2018;7(1):12. http://dx.doi.org/10.1038/s41426-018-0022-4

7. Ruan Y, Tian T, Zhu ZL, Hao YW, Zhang L, Zhu TJ, et al. Assessing competence for helminthiases: a lesson learnt from national contest of parasitic diseases in China in 2012-2016. Acta Trop 2019;198:105078 http://dx.doi.org/10.1016/j.actatropica.2019.105078.

8. Yin JH, Yan H, Huang F, Li M, Xiao HH, Zhou SS, et al. Establishing a China malaria diagnosis reference laboratory network for malaria elimination. Malar J 2015;14:40. http://dx.doi.org/10.1186/s12936015-0556-z.

9. Hang DR, Zhang JF, Li W, Huang YX, Zhao S, Gao Q, et al. Establishment and operation of schistosomiasis diagnostic reference laboratory in Jiangsu Province. Chin J Schistosomiasis Control 2019;31(6):669- 72,675. http://dx.doi.org/10.16250/j.32.1374. 2019157. (In Chinese).

10. Qian MB. Clonorchiasis control: starting from awareness. Infect Dis Poverty 2014;3:33. http://dx.doi.org/10.1186/2049-9957-3-33. 